Araştırma Makalesi / Research Article

Geliş tarihi / Received: 03-01-2021

Kabul tarihi / Accepted: 27-01-2021

Atıf İçin: Akin Kazancioglu E, 2021. Bis(Sülfonamid) İhtiva Eden Kalkon Türevlerinin Etkin Bir Şekilde Sentezi ve Karakterizasyonu. Iğdır Üniversitesi Fen Bilimleri Enstitüsü Dergisi, 11(2): 1341-1353.

To Cite: Akin Kazancioglu E, 2021. Effective Synthesis and Characterization of Bis(Sulfonamide) Containing Chalcone. Journal of the Institute of Science and Technology, 11(2): 1341-1353.

\title{
Bis(Sülfonamid) İhtiva Eden Kalkon Türevlerinin Etkin Bir Şekilde Sentezi ve
} Karakterizasyonu

\section{Elif AKIN KAZANCIOĞLU ${ }^{1 *}$}

ÖZET: Bu çalışmada, sülfonamid içeren yeni kalkon türevleri hızlı ve etkili bir şekilde sentezlendi. Kalkon iskelet yapısının sentezi, baz katalize Claisen-Schmidt kondenzasyon reaksiyon yöntemi kullanılarak yapıld1. 4-metoksi asetofenon, 4-nitrobenzaldehit ve $\mathrm{NaOH}^{\prime}$ in reaksiyonu sonucu 3 nolu kalkon \%80 verimle sentezlendi. Elde edilen 1-(4-metoksifenil)-3-(4-nitrofenil)prop-2-en-1-on (3) bileşiğindeki, nitro fonksiyonel grubunun $\mathrm{SnCl}_{2} \cdot 2 \mathrm{H}_{2} \mathrm{O}$ ile indirgenmesiyle hedef bileşik 3-(4aminofenil)-1-(4-metoksifenil)prop-2-en-1-on (4) \%98 verimle elde edildi. Aminin (4), 3(triflorometil)benzensülfonil klorür, 4-florobenzensülfonil klorür, 4-metoksibenzensülfonil klorür, naftalen-1-sülfonil klorür, pridin-3-sülfonil klorür ve metansülfonil klorür ile reaksiyonu sonucu Alzheimer hastalığı başta olmak üzere birçok farklı terapötik uygulamada kullanılabilme potansiyeline sahip olan moleküllerin sentezi başarılı bir şekilde gerçekleştirildi.

Anahtar Kelimeler: Sülfonamid, Kalkon, Claisen-Schmidt Reaksiyonu

\section{Effective Synthesis and Characterization of Bis(Sulfonamide) Containing Chalcone}

ABSTRACT: In this study, new chalcone derivatives containing sulfonamide were synthesized rapidly and efficiently. The synthesis of the chalcone skeletal structure was performed using the base-catalyzed Claisen-Schmidt condensation reaction method. Chalcone 3 was synthesized with $80 \%$ yield as a result of the reaction of 4-methoxy acetophenone, 4-nitrobenzaldehyde and $\mathrm{NaOH}$. Reduction of the nitro functional group in compound 1-(4-methoxyphenyl)-3-(4-nitrophenyl)prop-2-en-1-one (3) with $\mathrm{SnCl}_{2} .2 \mathrm{H}_{2} \mathrm{O}$ obtained the target compound 3-(4-aminophenyl)-1-(4-methoxyphenyl)prop-2-en-1-one (4) in $98 \%$ yield. The synthesis of target molecules that has the potential to be used in many different therapeutic applications, including Alzheimer's disease, has been successfully achieved as a result of the reaction of amine (4) with 3-(trifluoromethyl)benzenesulfonyl chloride, 4-fluorobenzenesulfonyl chloride, 4-methoxybenzenesulfonyl chloride, naphthalene-1-sulfonyl chloride, pyridine-3-sulfonyl chloride and methanesulfonyl chloride.

Keywords: Sulfonamide, Chalcone, Claisen-Schmidt Reaction

${ }^{1}$ Elif AKIN KAZANCIOĞLU (Orcid ID: 0000-0001-7486-685X), Kilis 7 Aralık Üniversitesi, Sağlık Hizmetleri Meslek Yüksekokulu, Kilis, Türkiye

*Sorumlu Yazar/Corresponding Author: Elif AKIN KAZANCIOĞLU, e-mail: eakazancioglu@kilis.edu.tr 


\section{GíRiș}

Sülfonamidler, Karbonik anhidraz (CA) inhibitörleri veya aktivatörleri olarak kullanılan ve antikanser, antifungal, antiobesite, antibakteriyel, antidiüretik, antiglokom ve antiepileptik gibi geniş biyolojik aktivitelere sahip olan bileşiklerdir (Supuran, 2008; Akin Kazancioglu ve ark., 2012). Bu nedenle, çok eski zamanlardan beri tıp alanında kullanılmaktadır. Sülfonamidler bakteri enfeksiyonlarının tedavisinde de kullanılan etkin kemoterapötiklerdir Piyasada bulunan sülfonamid türevi ilaçlar; antimikrobiyal, şeker düşürücü, idrar söktürücü sülfamidler gibi çeşitli gruplarda sinıflandırılabilmektedir. Asetazolamid, sülfadiazin, sülfapiridin ve nimesulide en sık kullanılan sülfonamid türevi ilaçlardır (Akin Kazancioglu ve Senturk, 2020). Yapılan araştırmalar bazı sülfonamid türevi bileşiklerin in vitro ve in vivo olarak önemli antitümör aktiviteye sahip olduğunu göstermektedir (Fidan ve ark., 2015).

Kalkonlar çok sayıda doğal ürünün iskelet yapısını oluşturan ve geniş biyolojik aktive gösteren önemli bileşiklerdir (Zhuang ve ark., 2017). Kalkonlar flavonoid türü bileşikler olup hem doğal hem de sentetik olarak elde edilebilmektedir. Bu nedenle kalkon ve türevlerine olan ilgi giderek artmakta ve özellikle biyolojik aktiviteleri üzerine birçok çalışmalar yapılmaktadır (Kocyigit ve ark., 2020). Kalkonlar; sentez kolaylığı, basit kimyası ve çok sayıda değişik fonksiyonel grubun yapıya kolayca ilave edilip hızlı bir şekilde türevlendirilebilmesinden dolayı birçok biyolojik aktivite çalışmasında tercih edilen iskelet yapılardır (Burmaoglu ve ark., 2020). Yapılan araştırmalar kalkonların; antibakteriyel, antimalaryal, antiviral, antiprotozoal, antikanser, anti-inflamatuar, sitotoksik, anti-HIV, antimikrobiyal etki, ayrıca protein tirozin fosfataz, aldoz redüktaz ve hCA inhibitör aktivitesi gösterdiğini ortaya koymuştur (Mathew ve ark., 2017; Kocyigit ve ark., 2017; Kocyigit ve ark., 2018). Kalkonların yapılarında bulunan, üç karbon atomundan oluşan, $\alpha, \beta$-doymamış karbonil grubu, elektronların hareketini sağladığı için kimyasal olarak bu yapıları önemli kılmaktadır. Bu nedenle de heterosiklik bileşiklerin sentezinde başlangıç maddesi olarak tercih edilmektedir. (Yazdan ve ark., 2015).

Son yıllarda bazı aktif yapıların birlikte kullanılması sonucu oluşturulan, hibrit moleküllerin sentezi hızla artmaktadır. Yeni sentezlenen hibrit türevlerin aktivitesinin, öncü moleküllerden daha etkin olduğu gözlenmektedir (Dong ve ark., 2010). Bu çalışma kapsamında da çeşitli hastalıkların tedavisinde kullanılan kalkon ve sülfonamid yapıları bir araya getirilerek potansiyel aktif moleküllerin sentezlenmesi planlanmıştır. Kim ve arkadaşları tarafından sentezlenen ve aktivite çalışmaları yapılan Sülfonamid içeren kalkon türelerinin etkisini gösteren patent çalışması, bu hipotezi desteklemektedir (U.S. Patent No. US20200190024, 2020).

\section{MATERYAL VE YÖNTEM}

\section{Materyaller ve Cihazlar}

$\mathrm{Bu}$ çalışmada ticari olarak temin edilen reaktifler, herhangi bir ilave saflaştırma yapılmaksızın doğrudan kullanılmıştır. Çalışmamızdaki reaksiyonlar aksi belirtilmedikçe azot atmosferi altında gerçekleştirilmiştir. Susuz çözücüler, kullanımdan önce uygun kurutma maddeleri üzerinden damıtıldı. ${ }^{1} \mathrm{H}$ ve ${ }^{13} \mathrm{C}$ NMR Spektrumları Bruker 400 spektrometre; Erime noktaları ise Stuart erime noktası SMP30 aparatı kullanılarak açık cam kapiler içinde belirlendi. Kromatografik saflaştırma işlemleri, silica-gel (230-400 gözenek, 40-63 um) kullanılarak ve artan polariteye sahip hekzan / EtOAc karışımları ile gerçekleştirildi. Reaksiyonların seyri, ince tabaka kromatografisi ile izlendi. Lekelerin tespiti için İTC (ince tabaka kromatografi) plakaları UV ışığına (254 ve $365 \mathrm{~nm}$ ) maruz bırakıldı. 


\section{Kalkon Yapısındaki Sülfonamid Türevlerinin Sentezi}<smiles>COc1ccc(C(=O)/C=C/c2ccc([N+](=O)[O-])cc2)cc1</smiles>

\section{(3)'ün sentez yöntemi:}

4-metoksi asetofenon (1) (1 eşdeğer), 4-nitrobenzaldehit (2) (1.2 eşdeğer) ve $\mathrm{NaOH}$ (3 eşdeğer), EtOH (2.5 mL / mmol substrat) içerisinde 3 gün karıştırıldı. 3 gün sonra reaksiyon karışımı $2 \mathrm{M} \mathrm{HC1}$ çözeltisi kullanılarak nötralize edildi. Meydana gelen çökelti süzülerek alındı ve EtOAc/Su $(2 \mathrm{~mL} / \mathrm{mmol}$ substrat x 3) kullanılarak ekstrakte edildi. Birleştirilen organik fazlar $\mathrm{Na}_{2} \mathrm{SO}_{4}$ üzerinden kurutuldu ve çözücü evaparatörde uzaklaştırıldı. Ham ürün EtOAc:Hekzan (1:4) kullanarak silika-gel üzerinden, kolon kromatografisi yöntemi kullanılarak saflaştırıldı. Sarı renkli katı (\%80 verim). ${ }^{1} \mathrm{H}-\mathrm{NMR}$ (400 $\left.\mathrm{MHz}, \mathrm{CDCl}_{3}, \mathrm{ppm}\right): \delta 8.30(\mathrm{~d}, \mathrm{~J}=8.8 \mathrm{~Hz}, 2 \mathrm{H}), 8.08(\mathrm{~d}, \mathrm{~J}=8.9 \mathrm{~Hz}, 2 \mathrm{H}), 7.87-7.74(\mathrm{~m}, 3 \mathrm{H}), 7.67$ (d, J $=15.7 \mathrm{~Hz}, 1 \mathrm{H}), 7.03(\mathrm{~d}, \mathrm{~J}=8.9 \mathrm{~Hz}, 2 \mathrm{H}), 3.93(\mathrm{~s}, 3 \mathrm{H})$.

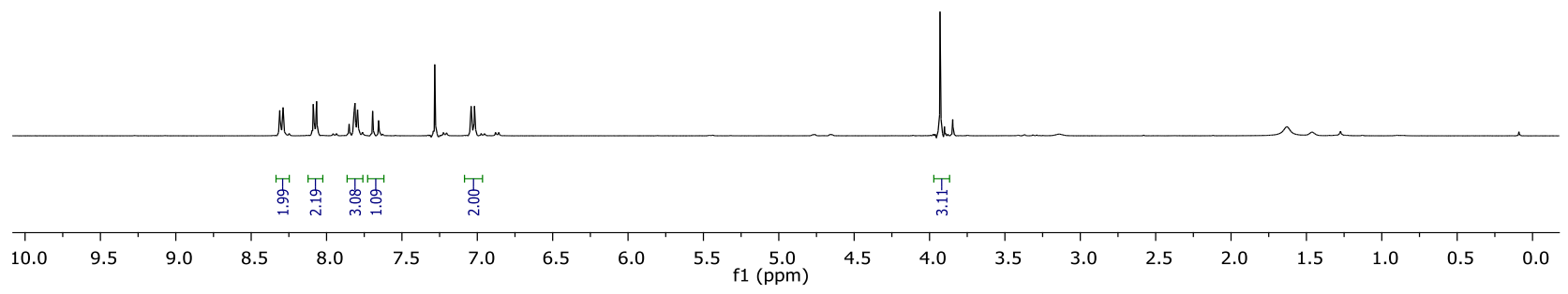

Şekil 1. (3)'ün ${ }^{1} \mathrm{H}$ NMR spektrumu<smiles>COc1ccc(C(=O)/C=C/c2ccc(N)cc2)cc1</smiles>

\section{(4)'ün sentez yöntemi:}

Kalkon (3) (1 eşdeğer) ve $\mathrm{SnCl}_{2} \cdot 2 \mathrm{H}_{2} \mathrm{O}$ (5 eşdeğer)'ün EtOH içerisindeki karışımı reflüks sıcaklığında 2.5 saat karıştırıldı. Daha sonra su ilave edilerek durdurulan reaksiyon, doygun $\mathrm{NaHCO}_{3}$ çözeltisi kullanılarak nötralize edildi. Reaksiyon karışımı EtOAc ile ekstrakte edildi. Birleştirilen organik fazlar $\mathrm{Na}_{2} \mathrm{SO}_{4}$ üzerinden kurutuldu ve çözücü evaparatörde uzaklaştırıldı. Reaksiyon \%98 verimle elde edildi ve ham ürün herhangi bir saflaştırma yapılmaksızın ileri kademelerde kullanıldı. ${ }^{1} \mathrm{H}$ NMR (400 MHz, $\left.\mathrm{CDCl}_{3}, \mathrm{ppm}\right) \delta 8.05(\mathrm{~d}, \mathrm{~J}=8.9 \mathrm{~Hz}, 2 \mathrm{H}), 7.77(\mathrm{~d}, \mathrm{~J}=15.5 \mathrm{~Hz}, 1 \mathrm{H}), 7.50$ (d, J = 8.4 Hz, 2H), $7.39(\mathrm{~d}, \mathrm{~J}=15.5 \mathrm{~Hz}, 1 \mathrm{H}), 6.99(\mathrm{~d}, \mathrm{~J}=8.9 \mathrm{~Hz}, 2 \mathrm{H}), 6.75-6.67(\mathrm{~m}, 2 \mathrm{H}), 3.91(\mathrm{~s}, 3 \mathrm{H})$. 


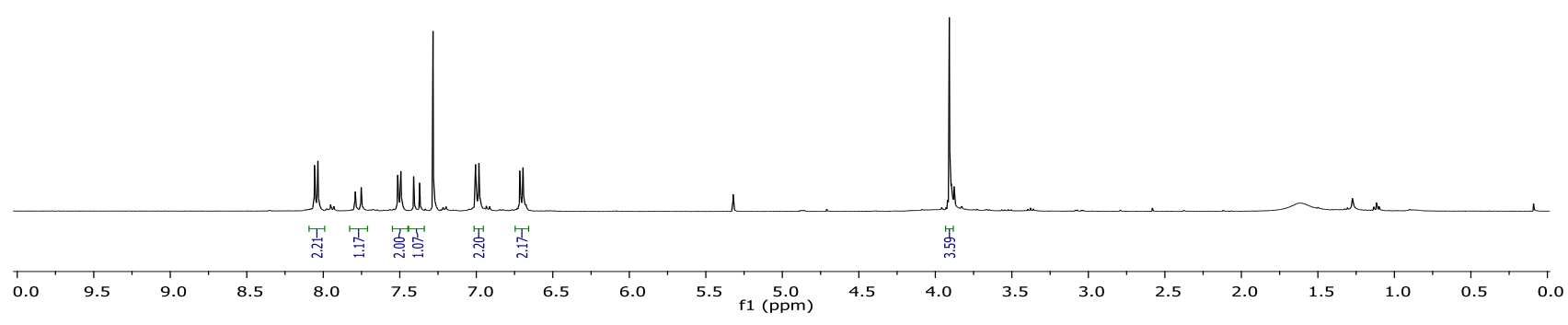

Şekil 2. (4)’ün ${ }^{1} \mathrm{H}$ NMR spektrumu

\section{Sülfonamid Türevlerinin Hazırlanması İçin Genel Yöntem}

Amin (4) (1 eşdeğer), $0{ }^{\circ} \mathrm{C}^{\prime}$ de DCM (metilen klorür) içerisinde çözüldü. Azot atmosferinde sırasıyla $\mathrm{NEt}_{3}$ (trietil amin) (2.17 eşdeğer) ve ilgili $\mathrm{MsCl}$ (mezitilklorür) (2.1 eşdeğer) türevi ilave edilerek oda sıcaklığına gelene kadar karıştırıldı. TLC ile çıkış bileşiğinin bitmesi takip edilerek, reaksiyon su ile durduruldu. Reaksiyon karışımı DCM ile ekstrakte edildi, doygun tuz çözeltisi ile yıkandı ve birleştirilen organik fazlar $\mathrm{Na}_{2} \mathrm{SO}_{4}$ üzerinden kurutuldu. Ham ürünler EtOAc:Hekzan kullanarak silika-gel üzerinden, kolon kromatografisi yöntemi kullanılarak saflaştırıldı.

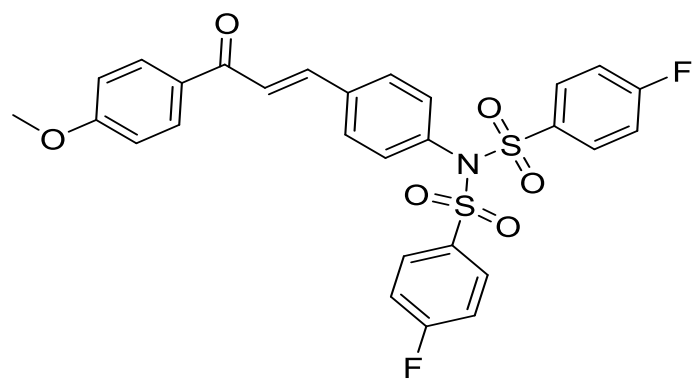

\section{(5)'in sentez yöntemi:}

Sar1 kat1; \%80 verim; E.N: $75-77{ }^{\circ} \mathrm{C}$; Rf:0.8 (Hekzan:EtOAc:\% 3:2); ${ }^{1} \mathrm{H}$ NMR $\left(400 \mathrm{MHz}, \mathrm{CDCl}_{3}\right.$, ppm) $\delta 8.04(\mathrm{~d}, \mathrm{~J}=8.7 \mathrm{~Hz}, 2 \mathrm{H}), 7.97(\mathrm{dd}, \mathrm{J}=8.7,4.9 \mathrm{~Hz}, 3 \mathrm{H}), 7.96-7.88(\mathrm{~m}, 2 \mathrm{H}), 7.76(\mathrm{~d}, \mathrm{~J}=15.6$ $\mathrm{Hz}, 1 \mathrm{H}), 7.63(\mathrm{~d}, \mathrm{~J}=8.3 \mathrm{~Hz}, 2 \mathrm{H}), 7.56(\mathrm{~d}, \mathrm{~J}=15.6 \mathrm{~Hz}, 1 \mathrm{H}), 7.41(\mathrm{~d}, \mathrm{~J}=8.2 \mathrm{~Hz}, 1 \mathrm{H}), 7.28-7.18(\mathrm{~m}$, 2H), $7.06(\mathrm{~d}, \mathrm{~J}=8.2 \mathrm{~Hz}, 2 \mathrm{H}), 6.99(\mathrm{~d}, \mathrm{~J}=8.8 \mathrm{~Hz}, 2 \mathrm{H}), 6.96-6.88(\mathrm{~m}, 1 \mathrm{H}), 3.90(\mathrm{~s}, 3 \mathrm{H}) ;{ }^{13} \mathrm{C}$ NMR $(100$ $\mathrm{MHz}, \mathrm{CDCl}_{3}$, ppm) $\delta 188.1,166.8,165.1,163.7,141.8,137.3,135.1,135.1,135.0,131.9,131.6,131.5$, 131.5, 131.4, 131.4, 130.9, 130.7, 130.5, 129.1, 127.4, 124.0, 116.6, 116.5, 116.4, 116.3, 114.0, 113.7, 55.5; IR (neat, $\mathrm{cm}^{-1}$ ) 1641, 1587, 1512, 1324, 1265, 1211, 1182, 1140, 1027, 951, 829.

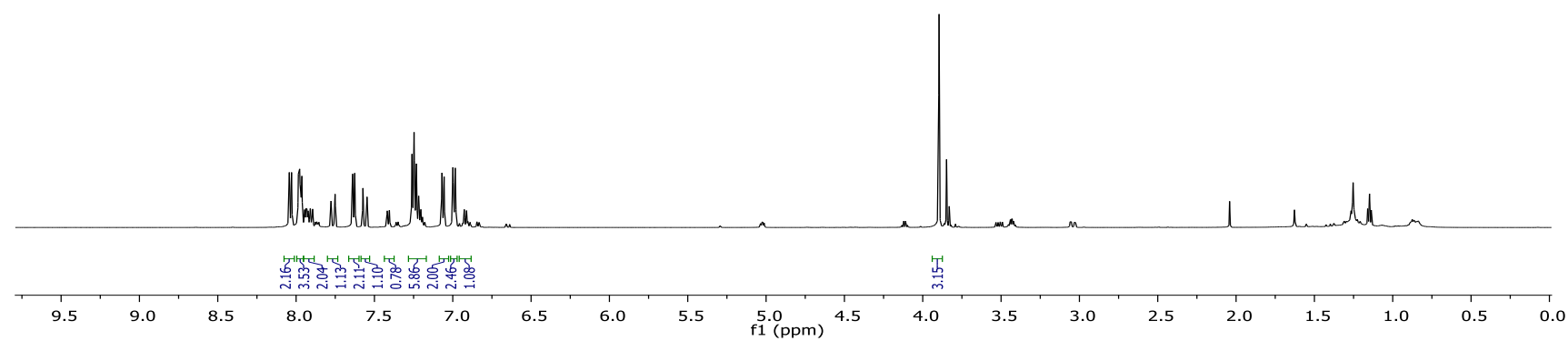

Şekil 3. (5)' in ${ }^{1} \mathrm{H}$ NMR spektrumu 


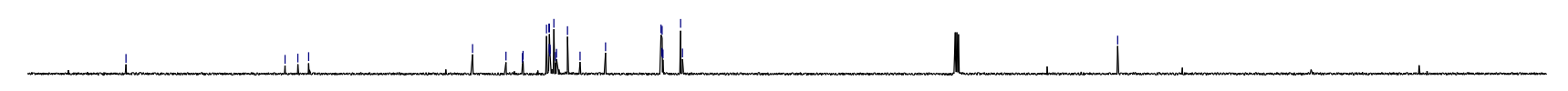

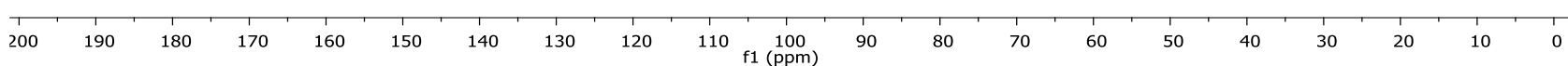

Şekil 4. (5)' in ${ }^{13} \mathrm{C}$ NMR spektrumu<smiles>COc1ccc(C(=O)/C=C/c2ccc(N(S(=O)(=O)c3cccc(C(F)(F)F)c3)S(=O)(=O)c3cccc(C(F)(F)F)c3)cc2)cc1</smiles>

\section{(6)'nun sentez yöntemi:}

Beyaz kat1; \%82 verim; E.N: 120-122 ${ }^{\circ} \mathrm{C}$; Rf:0.7 (Hekzan:EtOAc:\% 3:2); ${ }^{1} \mathrm{H}$ NMR (400 MHz, $\left.\mathrm{CDCl}_{3}, \mathrm{ppm}\right) \delta 8.26-8.14(\mathrm{~m}, 4 \mathrm{H}), 8.07(\mathrm{~d}, \mathrm{~J}=8.8 \mathrm{~Hz}, 2 \mathrm{H}), 8.01(\mathrm{~d}, \mathrm{~J}=7.9 \mathrm{~Hz}, 2 \mathrm{H}), 7.84-7.75(\mathrm{~m}$, 3H), 7.69 (d, J = 8.5 Hz, 2H), $7.60(\mathrm{~d}, \mathrm{~J}=15.7 \mathrm{~Hz}, 1 \mathrm{H}), 7.09$ (d, J = 8.4 Hz, 2H), 7.02 (d, J = 8.8 Hz, 2H), 3.93 (s, 3H); ${ }^{13} \mathrm{C}$ NMR (100 MHz, $\left.\mathrm{CDCl}_{3}, \mathrm{ppm}\right) \delta 188.1,163.7,141.6,140.1,137.8,134.5,132.1$, 131.8, 131.7, 131.5, 130.9, 130.7, 130.1, 129.2, 125.8, 125.8, 124.4, 124.3, 121.6, 114.0, 55.5; IR (neat, $\left.\mathrm{cm}^{-1}\right) 1651,1599,1509,1325,1260,1221,1162,1130,1021,911,821$.

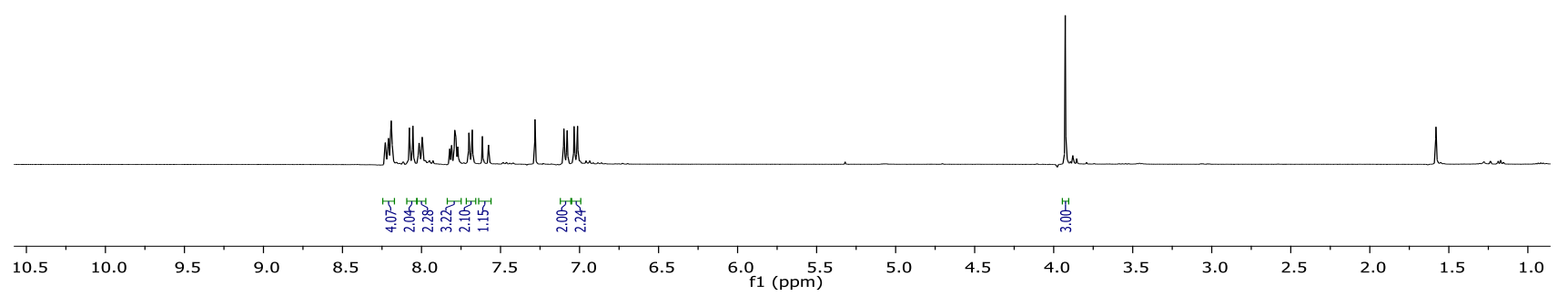

Şekil 5. (6)'nın ${ }^{1} \mathrm{H}$ NMR spektrumu 


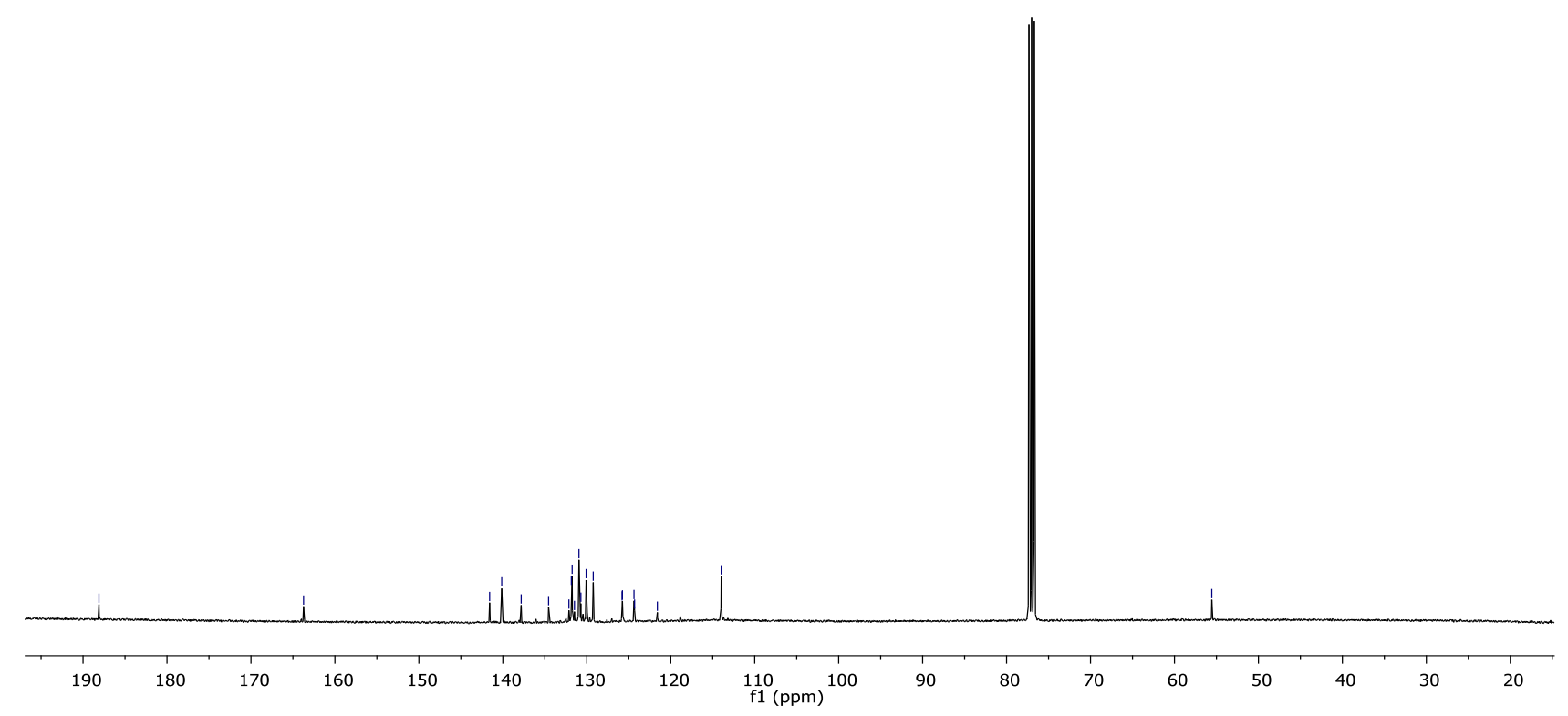

Şekil 6. (6)'nın ${ }^{13} \mathrm{C}$ NMR spektrumu<smiles>COc1ccc(C(=O)/C=C/c2ccc(N(c3ccc(S(=O)(=O)c4ccc(C)cc4)cc3)S(=O)(=O)c3ccc(C)cc3)cc2)cc1</smiles>

\section{(7)'nin sentez yöntemi:}

Açık sarı katı; \%76 verim; E.N: 178-180 ${ }^{\circ} \mathrm{C}$; Rf:0.6 (Hekzan:EtOAc \% 3:2); ${ }^{1} \mathrm{H}$ NMR (400 MHz, $\left.\mathrm{CDCl}_{3}, \mathrm{ppm}\right) \delta 8.03(\mathrm{~d}, \mathrm{~J}=8.7 \mathrm{~Hz}, 2 \mathrm{H}), 7.82(\mathrm{~d}, \mathrm{~J}=8.2 \mathrm{~Hz}, 3 \mathrm{H}), 7.77(\mathrm{t}, \mathrm{J}=12.5 \mathrm{~Hz}, 2 \mathrm{H}), 7.61(\mathrm{~d}, \mathrm{~J}=$ $8.2 \mathrm{~Hz}, 2 \mathrm{H}), 7.55(\mathrm{~d}, \mathrm{~J}=15.6 \mathrm{~Hz}, 1 \mathrm{H}), 7.38-7.30(\mathrm{~m}, 4 \mathrm{H}), 7.07(\mathrm{~d}, \mathrm{~J}=8.2 \mathrm{~Hz}, 2 \mathrm{H}), 6.99$ (d, J = 8.7 Hz, 2H), 3.90 (s, 3H), 2.48 (s, 6H).; ${ }^{13} \mathrm{C}$ NMR (100 MHz, $\left.\mathrm{CDCl}_{3}, \mathrm{ppm}\right) \delta 188.23,163.54,145.21,142.13$, $136.95,136.50,135.63,132.09,130.90,129.68,128.90,128.60,127.13,123.78,113.96,55.54,21.74$; IR (neat, $\left.\mathrm{cm}^{-1}\right)$ 1643, 1587, 1519, 1333, 1263, 1211, 1134, 1102, 1025, 942.

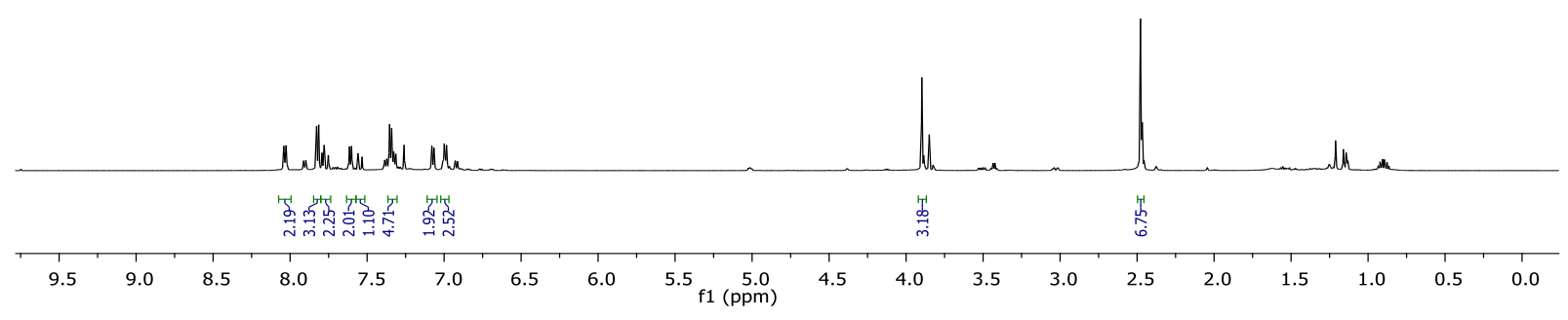

Şekil 7. (7)'nin ${ }^{1} \mathrm{H}$ NMR spektrumu 


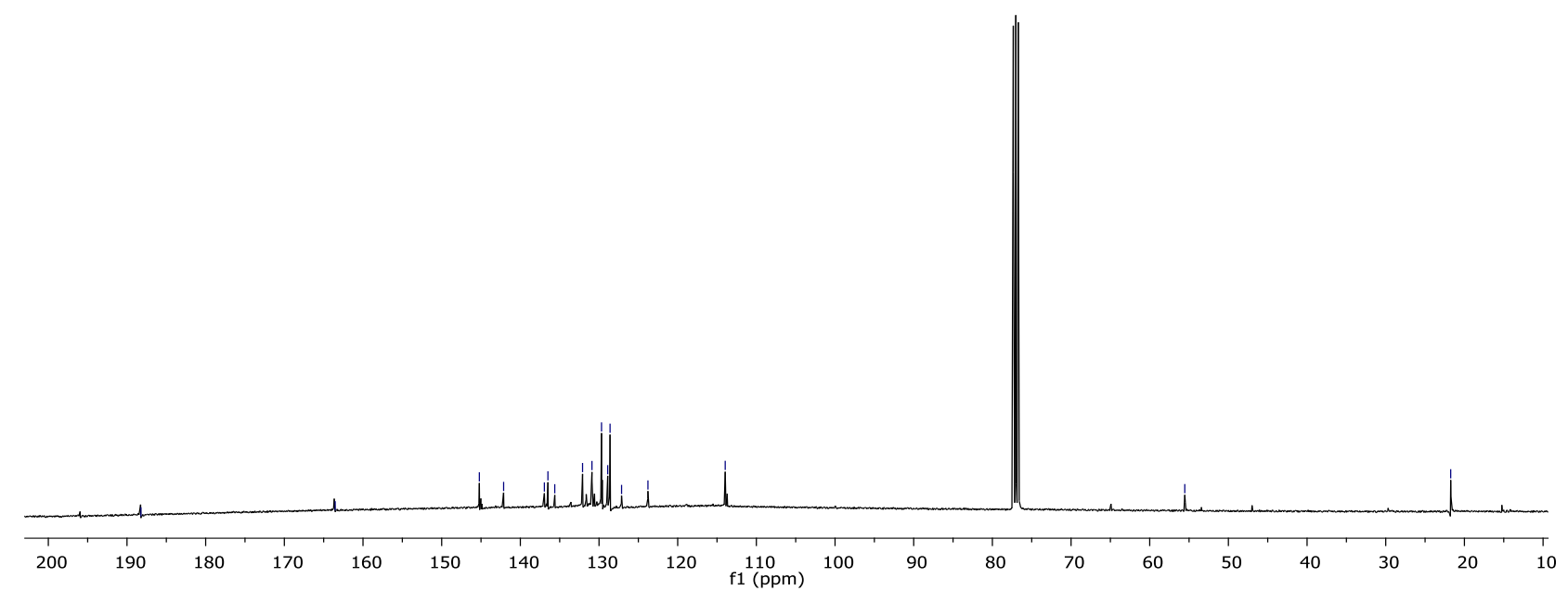

Şekil 8. (7)'nin ${ }^{13} \mathrm{C}$ NMR spektrumu

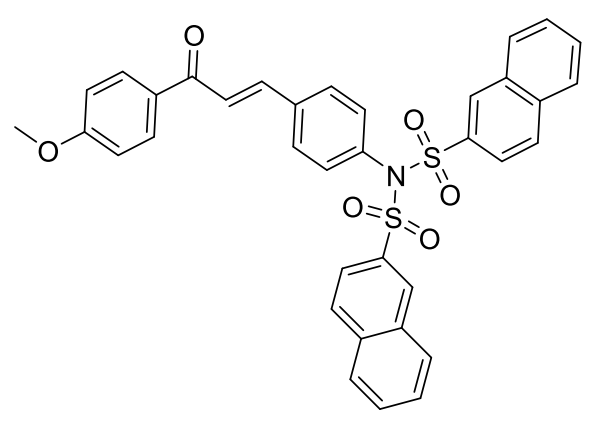

\section{(8)'in sentez yöntemi:}

Sar1 kat1; \%70 verim; E.N: 110-111 ${ }^{\circ} \mathrm{C}$; Rf:0.6 (Hekzan:EtOAc:\% 3:2); ${ }^{1} \mathrm{H}$ NMR (400 MHz, $\left.\mathrm{CDCl}_{3}, \mathrm{ppm}\right) \delta 8.51(\mathrm{~s}, 2 \mathrm{H}), 8.07-7.96(\mathrm{~m}, 10 \mathrm{H}), 7.82-7.71(\mathrm{~m}, 3 \mathrm{H}), 7.71-7.52(\mathrm{~m}, 5 \mathrm{H}), 7.13(\mathrm{~d}, \mathrm{~J}$ $=8.4 \mathrm{~Hz}, 2 \mathrm{H}), 7.01(\mathrm{~d}, \mathrm{~J}=8.8 \mathrm{~Hz}, 2 \mathrm{H}), 3.92(\mathrm{~s}, 3 \mathrm{H}) ;{ }^{13} \mathrm{C} \mathrm{NMR}\left(100 \mathrm{MHz}, \mathrm{CDCl}_{3}, \mathrm{ppm}\right) \delta 188.2,163.7$, 142.0, 137.1, 136.1, 135.4, 132.2, 131.9, 130.9, 130.8, 130.6, 130.6, 129.7, 129.6, 129.4, 129.0, 128.0, 127.8, 123.9, 123.0, 114.0, 29.7; IR (neat, $\mathrm{cm}^{-1}$ ) 1662, 1608, 1506, 1391, 1324, 1258, 1168, 1138, 1070, $923,807$.

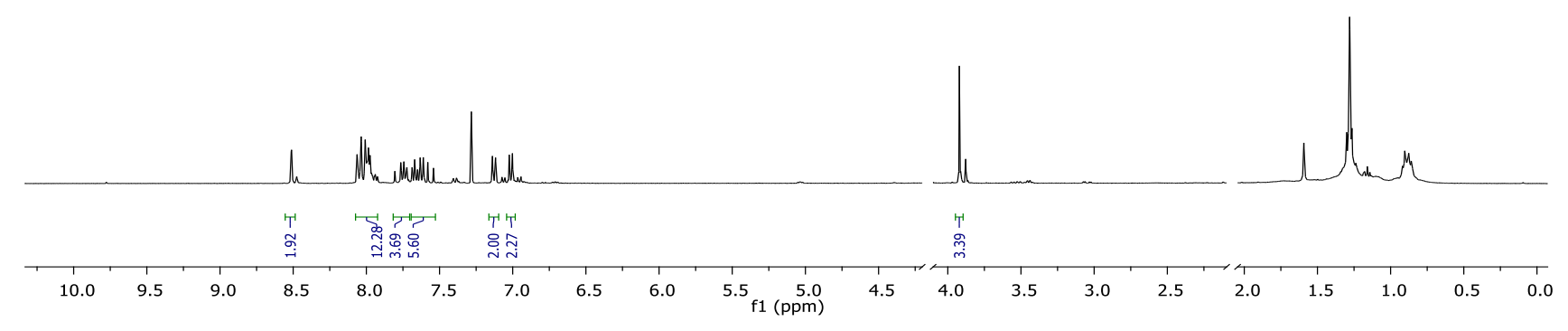

Şekil 9. (8)' in ${ }^{1} \mathrm{H}$ NMR spektrumu 


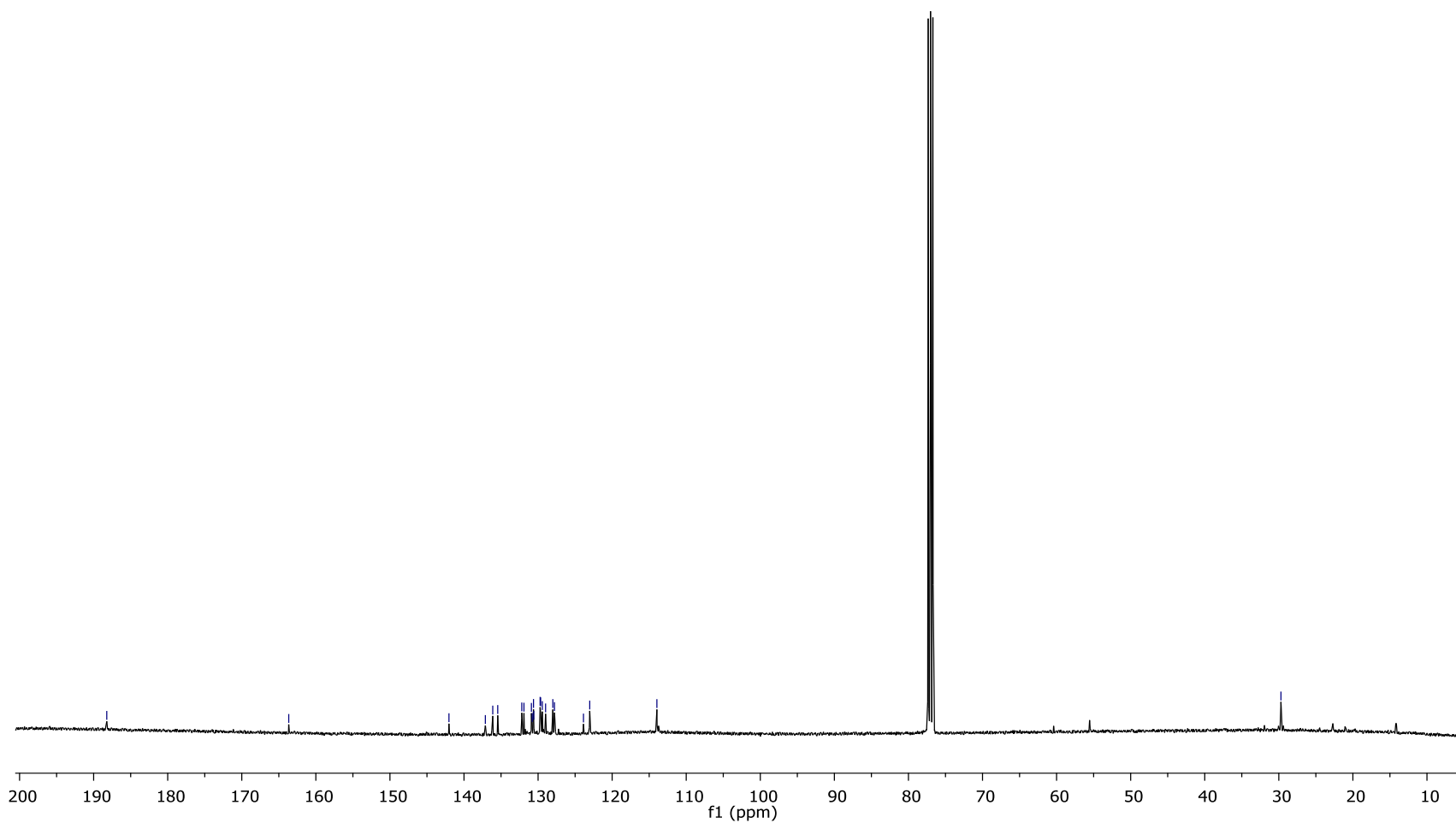

Şekil 10. (8)' in ${ }^{13} \mathrm{C}$ NMR spektrumu<smiles>COc1ccc(C(=O)/C=C/c2ccc(N(S(=O)(=O)c3cccnc3)S(=O)(=O)c3cccnc3)cc2)cc1</smiles>

\section{(9)'un sentez yöntemi:}

Sar1 kat1; \%65 verim; E.N: 140-142 ${ }^{\circ} \mathrm{C}$; Rf:0.2 (Hekzan:EtOAc:\% 3:2); ${ }^{1} \mathrm{H}$ NMR (400 MHz, $\left.\mathrm{CDCl}_{3}, \mathrm{ppm}\right) \delta 9.07(\mathrm{~d}, \mathrm{~J}=2.3 \mathrm{~Hz}, 2 \mathrm{H}), 8.96(\mathrm{dd}, \mathrm{J}=4.8,1.6 \mathrm{~Hz}, 2 \mathrm{H}), 8.37$ (ddd, J = 8.1, 2.3, $1.7 \mathrm{~Hz}$, 2H), $8.06(\mathrm{~d}, \mathrm{~J}=8.9 \mathrm{~Hz}, 2 \mathrm{H}), 7.80(\mathrm{~d}, \mathrm{~J}=15.7 \mathrm{~Hz}, 1 \mathrm{H}), 7.70(\mathrm{~d}, \mathrm{~J}=8.5 \mathrm{~Hz}, 2 \mathrm{H}), 7.64-7.55(\mathrm{~m}, 3 \mathrm{H})$, $7.12(\mathrm{~d}, \mathrm{~J}=8.4 \mathrm{~Hz}, 2 \mathrm{H}), 7.02(\mathrm{~d}, \mathrm{~J}=8.9 \mathrm{~Hz}, 2 \mathrm{H}), 3.92(\mathrm{~s}, 3 \mathrm{H}) ;{ }^{13} \mathrm{C} \mathrm{NMR}\left(100 \mathrm{MHz}, \mathrm{CDCl}_{3}, \mathrm{ppm}\right) \delta$ 188.1, 163.7, 154.7, 149.1, 141.5, 137.8, 136.4, 135.9, 134.3, 131.7, 130.9, 130.7, 129.4, 124.4, 123.9, 114.0, 55.6. IR (neat, $\mathrm{cm}^{-1}$ ) 1659, 1604, 1571, 1504, 1383, 1259, 1171, 1018, 910, 838.

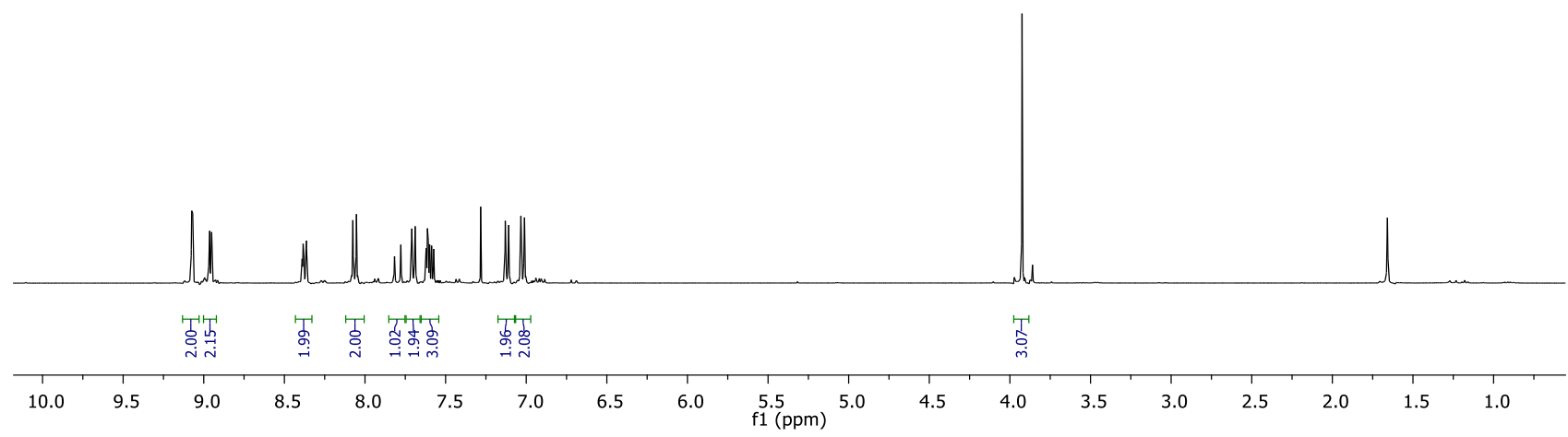

Şekil 11. (9)'un ${ }^{1} \mathrm{H}$ NMR spektrumu 


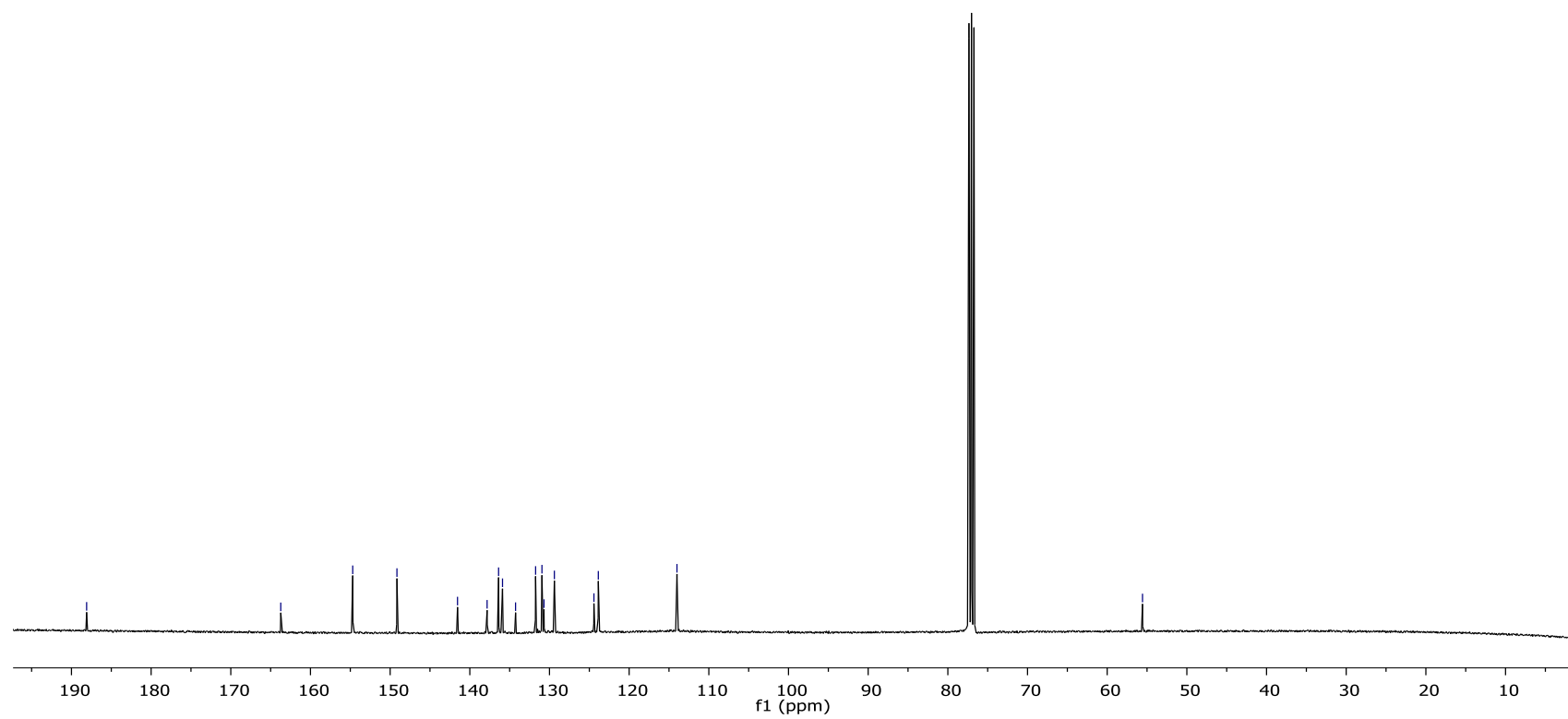

Şekil 12. (9)'un ${ }^{13} \mathrm{C}$ NMR spektrumu<smiles>COc1ccc(C(=O)/C=C/c2ccc(N(S(C)(=O)=O)S(C)(=O)=O)cc2)cc1</smiles>

\section{(10)'un sentez yöntemi:}

Açık sarı katı; \%87 verim; E.N: 110-111 ${ }^{\circ} \mathrm{C}$; Rf:0.6 (Hekzan:EtOAc:\% 3:2); ${ }^{1} \mathrm{H}$ NMR (400 MHz, $\left.\mathrm{CDCl}_{3}, \mathrm{ppm}\right) \delta 8.05(\mathrm{~d}, \mathrm{~J}=8.8 \mathrm{~Hz}, 2 \mathrm{H}), 7.79(\mathrm{~d}, \mathrm{~J}=15.7 \mathrm{~Hz}, 1 \mathrm{H}), 7.74(\mathrm{~d}, \mathrm{~J}=8.3 \mathrm{~Hz}, 2 \mathrm{H}), 7.58(\mathrm{~d}, \mathrm{~J}=$ $15.7 \mathrm{~Hz}, 1 \mathrm{H}), 7.43(\mathrm{~d}, \mathrm{~J}=8.3 \mathrm{~Hz}, 2 \mathrm{H}), 7.02(\mathrm{~d}, \mathrm{~J}=8.8 \mathrm{~Hz}, 2 \mathrm{H}), 3.92(\mathrm{~s}, 3 \mathrm{H}), 3.45(\mathrm{~s}, 6 \mathrm{H})$; ${ }^{13} \mathrm{C} \mathrm{NMR}$ $\left(100 \mathrm{MHz}, \mathrm{CDCl}_{3}, \mathrm{ppm}\right) \delta 188.2,163.7,141.7,137.4,134.5,131.2,130.9,130.7,129.3,124.1,114.0$, 55.5, 42.7.; IR (neat, $\mathrm{cm}^{-1}$ ) 2923, 1663, 1598, 1507, 1365, 1324, 1258, 1219, 1158, 1020, 977, 907.

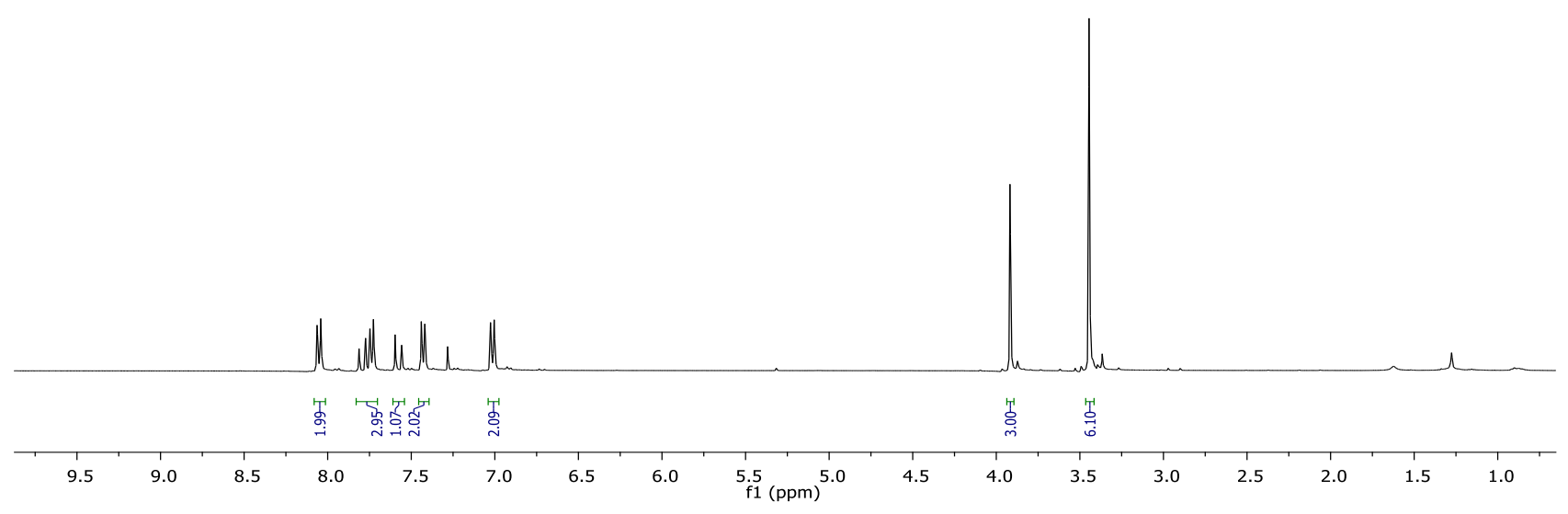

Şekil 13. (10)'un ${ }^{1} \mathrm{H}$ NMR spektrumu 


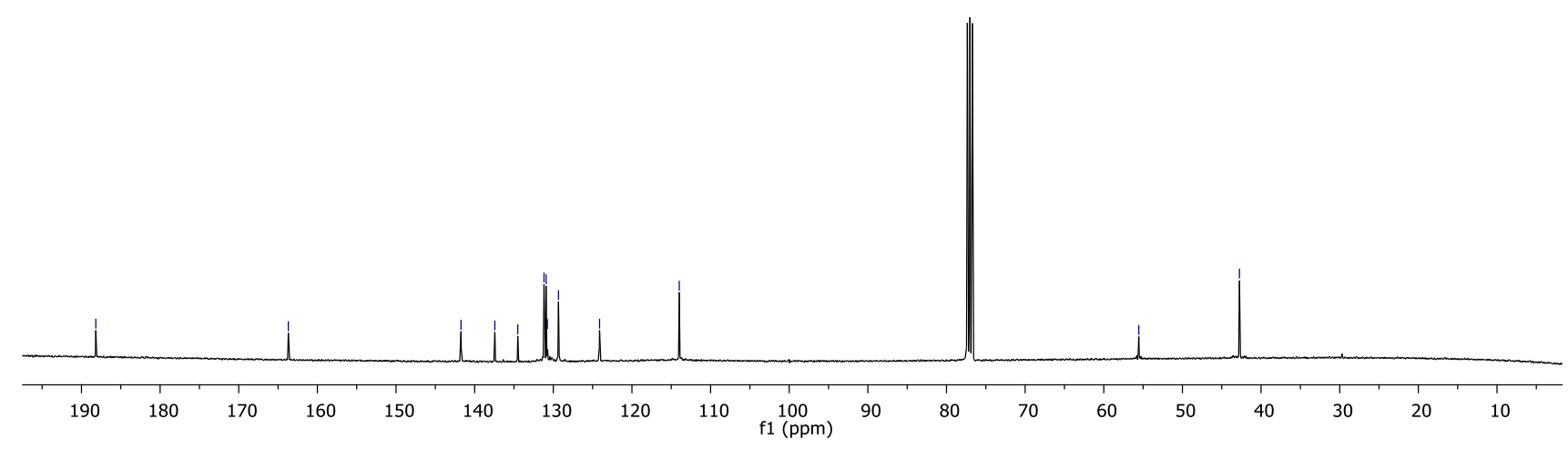

Şekil 14. (10)'un ${ }^{13} \mathrm{C}$ NMR spektrumu

\section{BULGULAR VE TARTIŞMA}

$\mathrm{Bu}$ araştırmada, sentetik kimyacıların ve farmakologların oldukça ilgisini çeken kalkon türevlerinin sentezi ve bu türevlerin çeşitli hetero-sülfonil klorürler ile tepkimeleri sonucunda, biyoaktif olma potansiyeline sahip olan kalkon-sülfonamid bileşikleri türetildi.

Kalkonların sentezi; Suzuki, Heck, Julia-Kocienski, Wittig gibi coupling reaksiyonları, FridelCraft açilasyon reaksiyonu ve photo-Fries düzenlenme reaksiyon yöntemi kullanılarak yapılabilmektedir. Fakat bu yöntemlerde kullanılan katalizörlerin pahalı olması, özel gaz kullanım zorunluluğu ve uygun reaktif bulmadaki zorluklar bu yöntemlerin dezavantajlarıdır (Evranos Aksöz ve Ertan, 2011; Zhuang ve ark., 2017). Bundan dolayı hedef bileşiklerin iskelet yapısını sentezlemek için; asit veya baz katalizli Claisen-Schmidt kondenzasyon reaksiyon yöntemi tercih edildi.

Çıkış bileşiği olan kalkon (3); ucuz ve kolay uygulanabilir bir yöntem olması nedeniyle baz katalize Claisen-Schmidt kondenzasyon reaksiyon yöntemi kullanılarak sentezlendi. İlk olarak 4metoksiasetofenon (1 eş değer)'un $\mathrm{MeOH}$ içindeki çözeltisine, 4-nitrobenzaldehit (1.6 eş değer) ve $\mathrm{KOH}$ (\%50 sulu çözeltisi) ilave edilerek oda sıcaklığında 15 saat karıştırıldı (Burmaoglu ve ark., 2020). Çıkış bileşiğinin bitişi İTK ile takip edildi ve gerekli ekstraksiyon işlemleri yapıldı. Sonuç olarak ürün karışımı oluştuğu ve hedef bileşiğin veriminin düşük olması nedeniyle başka bir baz kullanılmasına karar verildi. 1-(4-metoksifenil)-3-(4-nitrofenil)prop-2-en-1-on (3)'ün sentezi için, yine aynı çıkış bileşikleri olan 4metoksiasetofenon ve 4-nitrobenzaldehit' in $\mathrm{EtOH}$ içerisindeki çözeltisine $\mathrm{NaOH}$ ilave edilerek çıkış bileşiği bitene kadar karıştırıldı. Çıkış bileşiği bittiğinde, reaksiyon karışımı $2 \mathrm{M}$ HC1 çözeltisi kullanılarak nötralize edildi ve meydana gelen katı süzülerek alındı (Sonmez ve ark., 2011). Elde edilen katı ileri bir saflaştırmaya tabi tutulmadan bir sonraki kademeye geçilebilir. Fakat bilindiği üzere saf madde ile kurulacak olan reaksiyonların verimi daha yüksek olmaktadır. Bunun için elde edilen katının saflaştırılmasına karar verildi. Ham ürün, gerekli ekstraksiyon işlemlerine tabi tutulduktan sonra kolon kromatografisi yöntemi kullanılarak saflaştırıldı ve \%80 verimle 1-(4-metoksifenil)-3-(4nitrofenil)prop-2-en-1-on (3) elde edildi (Şekil 15). 3 numaralı bileşiğin NMR spektrumu incelendiğinde; $\alpha, \beta$-doymamış olefin protonlarının, 7.5-8.1 ppm arasında dublet şeklinde gelmesi ve bu piklerin etkileşim sabitlerinin yaklaşık $J=15.0 \mathrm{~Hz}$ olarak ölçülmesi kalkon yapısının oluştuğunu göstermektedir. 


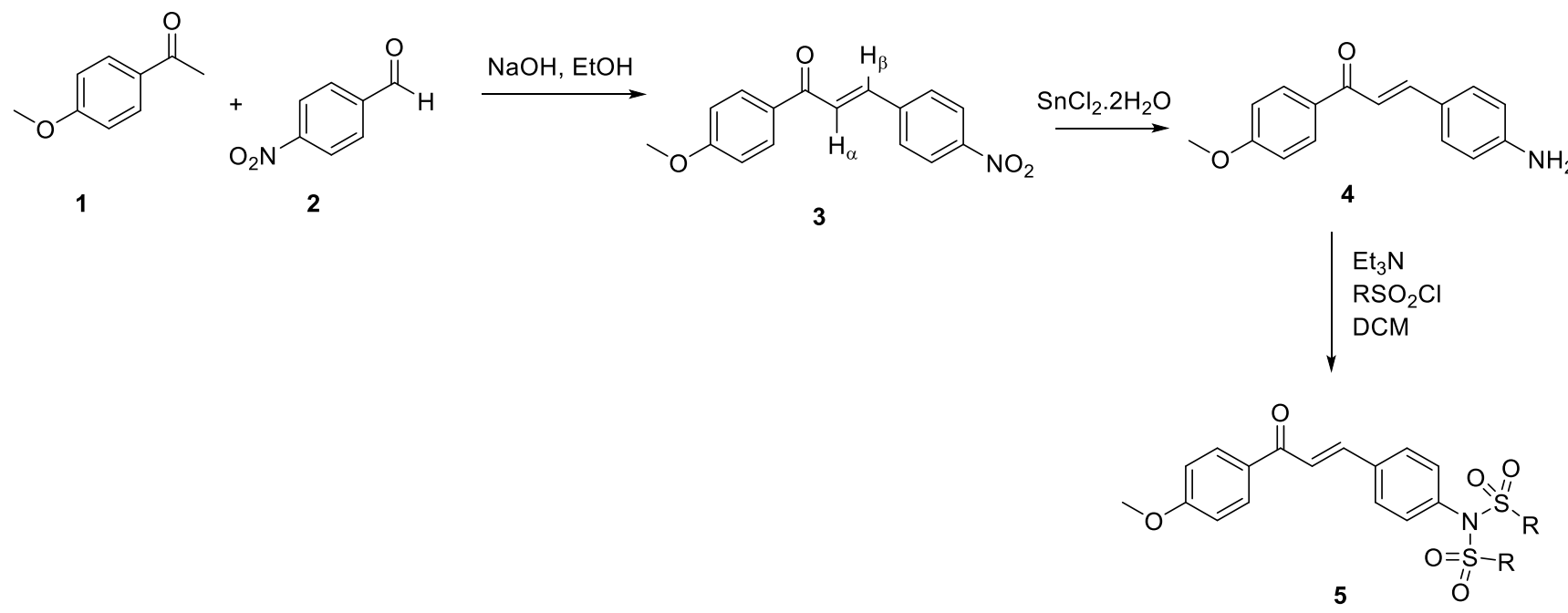

Şekil 15. Kalkon Yapısındaki Sülfonamid Türevlerinin Sentez Planı<smiles>[R]S(=O)(=O)N(c1ccc(/C=C/C(=O)c2ccc(OC)cc2)cc1)S([R])(=O)=O</smiles><smiles>COc1ccc(C(=O)/C=C/c2ccc(N(S(=O)(=O)c3ccc(F)cc3)S(=O)(=O)c3ccc(F)cc3)cc2)cc1</smiles>

5<smiles>COc1ccc(C(=O)/C=C/c2ccc(N(S(=O)(=O)c3ccc4ccccc4c3)S(=O)(=O)c3ccc4ccccc4c3)cc2)cc1</smiles><smiles>COc1ccc(C(=O)/C=C/c2ccc(N(S(=O)(=O)c3cccc(C(F)(F)F)c3)S(=O)(=O)c3cccc(C(F)(F)F)c3)cc2)cc1</smiles>

6<smiles>COc1ccc(C(=O)/C=C/c2ccc(N(c3ccc(S(=O)(=O)c4cccnc4)cc3)S(=O)(=O)c3cccnc3)cc2)cc1</smiles><smiles>COc1ccc(C(=O)/C=C/c2ccc(N(S(=O)(=O)c3ccc(C)cc3)S(=O)(=O)c3ccc(C)cc3)cc2)cc1</smiles><smiles>COc1ccc(C(=O)/C=C/c2ccc(N(S(C)(=O)=O)S(C)(=O)=O)cc2)cc1</smiles>

Şekil 16. Sülfonamid içeren kalkon türevlerinin açık yapısı

3-(4-aminofenil)-1-(4-metoksifenil)prop-2-en-1-on (4) bileşiğinin sentezi için, (3)'deki nitro ($\mathrm{NO}_{2}$ ) fonksiyonel grubunun, amine $\left(-\mathrm{NH}_{2}\right)$ indirgenmesi gerekmektedir. Bunun için $\mathrm{Pd}-\mathrm{C} / \mathrm{H}_{2}, \mathrm{SnCl}_{2}$, $\mathrm{HSiCl}_{3}, \mathrm{Fe} / \mathrm{CaCl}_{2}, \mathrm{Zn} / \mathrm{RuCl}_{2}\left(\mathrm{PPh}_{3}\right)_{2}$ gibi çeşitli indirgeyiciler literatürde kullanılmaktadır. 3 bileşiğinin yapısı incelenecek olursa; $\alpha, \beta$-doymamış karbonil fonksiyonel grubu bulunduğu için seçilecek olan indirgeyicinin sadece nitro grubunu indirgemesi gerekmektedir. Bu nedenle nitro grubunu serbest amine indirgemek için literatürde de yaygın olarak kullanılan $\mathrm{SnCl}_{2}$ indirgeyici olarak tercih edildi. 1-(4methoxyphenyl)-3-(4-nitrophenyl)prop-2-en-1-one (3), EtOH içerisinde $\mathrm{SnCl}_{2} \cdot 2 \mathrm{H}_{2} \mathrm{O}$ varlığında basınçlı tüp kullanılarak $70{ }^{\circ} \mathrm{C}$ de 2.5 saat 1 ștıldı. Çıkış bileşiğinin bittiği İTK (ince tabaka kromatografisi) ile tespit edildikten sonra, reaksiyon karışımı içerisindeki etanol evaporatörde uzaklaştırıldı. Metilen klorür 
ve doymuş $\mathrm{NaCl}$ çözeltisi ile ekstraksiyon işlemlerine tabi tutuldu. Dönüşüm \%98 olduğu için elde edilen ham ürün 3-(4-aminofenil)-1-(4-metoksifenil)prop-2-en-1-one (4) herhangi bir saflaştırma yapılmadan ileri basamakta kullanıldı (Şekil 15). $\mathrm{NO}_{2}$ fonksiyonel grubu taşıyan 3 ve $\mathrm{NH}_{2}$ fonksiyonel grubu taşıyan 4 bileşiklerinin IR spektrumları incelendiğinde; 4'ün IR spektrumunda $3400 \mathrm{~cm}^{-1}$ 'de gözlenen pikin $-\mathrm{NO}_{2}$ fonksiyonel grubunun $-\mathrm{NH}_{2}$ fonksiyonel grubuna indirgendiğini göstermektedir.

Elde edilen serbest amin 3-(4-aminofenil)-1-(4-metoksifenil)prop-2-en-1-on (4) ile hedef bileşiğimiz olan bis sülfonamid türevlerinin sentezine geçildi. Yapılan sülfonlama tepkimelerinde baz olarak trietilamin ve polar çözücü olarak metilen klorür kullanıldı. Şartların optimize edilmesi için öncelikli olarak serbest amin grubuna sahip kalkon (1 eş değer) bileşiği ile 4-florofenilsüfonil klorür (2 eş değer) tepkimeye tabi tutuldu. Tepkime $\mathrm{Et}_{3} \mathrm{~N}$ varlığında, $0^{\circ} \mathrm{C}$ 'de $\mathrm{DCM}$ içiresinde gerçekleştirildi. Çıkış bileşiğinin bitişi İTK kullanılarak kontrol edildi. Çıkış bileşiği bittikten sonra gerekli ekstraksiyon ve saflaştırma işlemleri yapıldı ve \%80 verimle 5 numaralı hedef bileşik başarılı bir şekilde elde edildi. Daha sonrasında aynı reaksiyon şartları 3-triflorometanbenzensülfonil klorür, 4-metilbenzensülfonil klorür, naftalen-2-sülfonil klorür, piridin-3-sülfonil klorür ve metansülfonil klorür bileşikleri ile tekrarlandı. Sonuç olarak, literatürde bilinmeyen 6 farklı bis sülfonamid türevi \%65 ile \%87 arasında verimlerle elde edildi (Şekil 16). Sentezi başarılı şekilde yapılan bis sülfonamid içeren kalkon türevlerinin ${ }^{1} \mathrm{H},{ }^{13} \mathrm{C}$ NMR ve IR (Infrared spektrometre) spektrumları alınarak yapı karakterizasyonu yapıldı (Şekil 1-14).

\section{SONUÇ}

Sonuç olarak çeşitli hastalıkların tedavisinde kullanılan kalkon ve sülfonamid yapıları bir araya getirilerek literatürde bilinmeyen, yeni 6 adet bis sülfonamid içeren kalkon türevlerinin sentezi \%65 ile $\% 87$ arasında oldukça iyi verimlerle gerçekleştirildi. Elde edilen bis sülfonamid içeren kalkon türevlerinin ${ }^{1} \mathrm{H},{ }^{13} \mathrm{C}$ NMR, erime noktas1 ve IR (Infrared spektrometre) spektrumları alınarak yap1 karakterizasyonu yapıldı. Ayrıca kalkonların sentezi sırasında kullanılan asetofenon ve aldehitlerin çok yönlü olarak türevlendirilmesiyle çok çeşitli bis sülfonamid içeren kalkon türevlerinin sentezinin mümkün olduğu elde edilen verilerle ortaya kondu. Elde edilen bileşiklerin daha etkili ilaç moleküllerinin hazırlanmasında ilaç öncüleri veya yapı taşları olarak da değerlendirilebileceği düşünülmektedir.

\section{TEŞEKKÜR}

$\mathrm{Bu}$ çalışma, Kilis 7 Aralık Üniversitesi Bilimsel Araştırma Projeleri Koordinasyon Birimi tarafından "12411" kodlu proje ile desteklenmiştir.

\section{Çıkar Çatışması}

Makaleye ait çalışmanın planlanması, yürütülmesi ve makalenin yazılması aşamalarında herhangi bir çıkar çatışması olmadığını beyan ederim.

\section{Yazar Katkısı}

Makalenin planlanması, yürütülmesi ve yazılması makale tek yazarı olarak tarafımca yapıldığı beyan ederim.

\section{KAYNAKLAR}

Akin Kazancioglu E, Guney M, Şentürk M, Supuran CT, 2010. Simple Methanesulfonates are Hydrolyzed by the Sulfatase Carbonic Anhydrase Activity. Journal of Enzyme Inhibition and Medicinal Chemistry, 27 (6): 880-885. 
Akin Kazancioglu E, Senturk M, 2020. Synthesis of N-Phenylsulfonamide Derivatives and İnvestigation of Some Esterase Enzymes Inhibiting Properties. Bioorganic Chemistry, 104:104279.

Burmaoglu S, Akin Kazancioglu E, Kaya R, Kazancioglu M, Karaman M, Algul O, Gulcin I, 2020. Synthesis of Novel Organohalogen Chalcone Derivatives and Screening of Their Molecular Docking Study and Some Enzymes Inhibition Effects, Journal of Molecular Structure, 1208:127868.

Dong X, Du L, Pan Z, Liu T, Yang B, Hu Y, 2010. Synthesis And Biological Evaluation of Novel Hybrid Chalcone Derivatives as Vasorelaxant Agents. European Journal Of Medicinal Chemistry, 45 (9): 39863992.

Evranos AB, Ertan R, 2011. Chemical and Structural Properties of Chalcones I. Farad Journal of Pharmaceutical Sciences, 36, 223-242.

Fidan I, Salmas RE, Arslan M, Şentürk M, Durdagi S, Ekinci D, Şentürk E, Coşgun S, Supuran CT, 2015. Carbonic Anhydrase Inhibitors: Design, Synthesis, Kinetic, Docking and Molecular Dynamics Analysis of Novel Glycine and Phenylalanine Sulfonamide Derivatives. Bioorganic \& Medicinal Chemistry, 23 (23): 7353-8.

Kim E, Namkoong K, Jeong J, Jang S, Kwon YJ, Jun KY, Jeon KH, Park M, Kim H, Na Y, 2020. Novel Compound and Pharmaceutical Composition Comprising Same as Active Ingredient. US Patent Aplication Publication, US20200190024.

Kocyigit UM, Budak Y, Eliguzel F, Taslimi P, K1lic D, Gulcin I, Ceylan M, 2017. Synthesis and Carbonic Anhydrase Inhibition of Tetrabromo Chalcone Derivatives. Archiv der Pharmazie, 350 (12).

Kocyigit UM, Budak Y, Gurdere MB, Erturk F, Yencilek B, Taslimi P, Gulcin I, Ceylan M, 2018. Synthesis of Chalcone-Imide Derivatives and Investigation of Their Anticancer and Antimicrobial Activities, Carbonic Anhydrase and Acetylcholinesterase Enzymes Inhibition Profiles. Archives of Physiology and Biochemistry, 124 (1):61-68.

Kocyigit UM, Gezegen H, Taslimi P, 2020. Synthesis, Characterization, and Biological Studies of Chalcone Derivatives Containing Schiff Bases: Synthetic Derivatives for the Treatment of Epilepsy and Alzheimer's Disease. Archiv der Pharmazie, 353 (12):e2000202.

Mathew B, Mathew GE, Ucar G, Joy M, Nafna EK, Lohidakshan KK, Suresh J, 2017. Monoamine Oxidase İnhibitory Activity of Methoxy-Substituted Chalcones. International Journal of Biological Macromolecules, 104 (Pt A), 1321-1329.

Sonmez F, Sevmezler S, Atahan A, Ceylan M, Demir D, Gencer N, Arslan O, Kucukislamoglu M, 2011. Evaluation of New Chalcone Derivatives as Polyphenol Oxidase İnhibitors. Bioorganic \& Medicinal Chemistry Letters. 15; 21(24): 7479-82.

Supuran CT, 2008. Carbonic Anhydrases: Novel Therapeutic Applications for Inhibitors and Activators. Nature Reviews Drug Discovery, 7 (2): 168-81.

Yazdan SK, Sagar DV, Shaik AB, 2015. Chemical and Biological Potentials of Chalcones: A Review. Organic \& Medicinal Chemistry International Journal, 1 (1), 1-9. 10.

Zhuang C, Zhang W, Sheng C, Zhang W, Xing C, Miao Z, 2017. Chalcone: A Privileged Structure In Medicinal Chemistry, Chemical Reviews, 117, 7762-7810. 